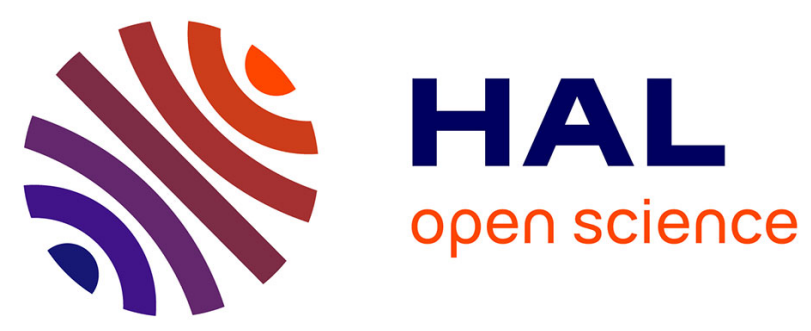

\title{
Leading point behavior during the ignition of an annular combustor with liquid n-heptane injectors
}

\author{
Théa Lancien, Kevin Prieur, Daniel Durox, Sébastien Candel, Ronan
}

Vicquelin

\section{- To cite this version:}

Théa Lancien, Kevin Prieur, Daniel Durox, Sébastien Candel, Ronan Vicquelin. Leading point behavior during the ignition of an annular combustor with liquid n-heptane injectors. Proceedings of the Combustion Institute, 2019, 37, pp.5021 - 5029. 10.1016/j.proci.2018.05.160 . hal-03484499

\section{HAL Id: hal-03484499 \\ https://hal.science/hal-03484499}

Submitted on 20 Dec 2021

HAL is a multi-disciplinary open access archive for the deposit and dissemination of scientific research documents, whether they are published or not. The documents may come from teaching and research institutions in France or abroad, or from public or private research centers.
L'archive ouverte pluridisciplinaire HAL, est destinée au dépôt et à la diffusion de documents scientifiques de niveau recherche, publiés ou non, émanant des établissements d'enseignement et de recherche français ou étrangers, des laboratoires publics ou privés.

\section{(c)(1) $\$$}

Distributed under a Creative Commons Attribution - NonCommerciall 4.0 International 
$37^{\text {th }}$ International Symposium on Combustion

\title{
Leading point behavior during the ignition of an annular combustor with liquid n-heptane injectors
}

\author{
T. Lancien ${ }^{a, 1}$, K. Prieur ${ }^{a, b}$, D. Durox ${ }^{a}$, S. Candel ${ }^{a}$, R. Vicquelin ${ }^{a}$ \\ ${ }^{a}$ Laboratoire EM2C, CNRS, CentraleSupélec, Université Paris-Saclay, 3 rue \\ Joliot Curie 91192 Gif Sur Yvette cedex, France \\ ${ }^{b}$ Safran Tech, EGSP, Chateaufort 78772 Magny-Les-Hameaux, France
}

\section{Colloquium: Gas Turbine and Rocket Engine Combustion}

Word Count: Method 2, counting from a two-column formatted version of the paper.

Paper length: 8 pages, Equivalent word count: 6200 words

Supplemental material: A list of supplemental material is included on the last page

All figures in the present article can be printed in black and white, however, if color printing is judged necessary, the author agree to pay color reproduction charges if applicable.

\footnotetext{
${ }^{1}$ Corresponding author: Théa Lancien, Laboratoire EM2C, CNRS, CentraleSupélec, Université Paris-Saclay, 3 rue Joliot Curie 91192 Gif Sur Yvette cedex, France Email: thea.lancien@centralesupelec.fr 


\title{
Leading point behavior during the ignition of an annular combustor with liquid n-heptane injectors
}

\author{
Théa Lancien ${ }^{\mathrm{a}, *}$, Kevin Prieur ${ }^{\mathrm{a}, \mathrm{b}}$, Daniel Durox ${ }^{\mathrm{a}}$, Sébastien Candel $^{\mathrm{a}}$, Ronan \\ Vicquelin $^{\mathrm{a}}$ \\ ${ }^{a}$ Laboratoire EM2C, CNRS, CentraleSupélec, Université Paris-Saclay, 3 rue Joliot Curie \\ 91192 Gif Sur Yvette cedex, France \\ ${ }^{b}$ Safran Tech, EESP, Chateaufort 78772 Magny-Les-Hameaux, France
}

\begin{abstract}
Experimental and numerical investigations of ignition in combustors with multiple burners have recently emerged and have provided new insights on the last phase of ignition in gas turbine-like annular geometries where the flame propagates from burner to burner. Previous comparisons between calculations and experiments of light-round in a laboratory scale annular combustion chamber have demonstrated the ability of large-eddy simulation to predict such processes for perfectly premixed conditions and, more recently, for n-heptane spray injection. The present analysis focuses on two additional operating points with liquid n-heptane sprays and the turbulent flame propagation in the two-phase mixture is examined through the behavior of its leading points. The validation of the light-round process is characterized in terms of ignition delays. The detailed analysis of the propagation through the definition of a leading point enables to highlight some key phenomena responsible for the flame behavior, such as the influence of the liquid droplet
\end{abstract}

\footnotetext{
*Corresponding author:

Email address: thea.lancien@centralesupelec.fr (Théa Lancien)
} 
spray and its vaporization in the chamber. Calculations indicate that the volumetric expansion due to the chemical reaction at the flame induces a strong azimuthal flow in the fresh stream at a distance of several sectors ahead of the flame, which modifies conditions in this region. This creates heterogeneities in the gas composition and wakes on the downstream side of the swirling jets formed by the injectors, with notable effects on the motion of the leading point and on the absolute flame velocity.

Keywords:

Two-phase flow, Large-Eddy Simulation, Ignition, Eulerian-Eulerian approach, Annular combustor

\section{Introduction}

One of the critical design issues of any aero-engine combustor is that of a smooth, safe and reliable ignition over a wide operability range. In the case of a multiple injector combustor, a successful ignition can typically be decomposed into three main stages [1]: The first two stages correspond to the flame kernel initiation and to the kernel's expansion and propagation to stabilize a flame on a single burner. The last stage of the ignition process involves the flame propagation from each ignited burner to the next until the full system is ignited. In the case of an annular chamber, this phase is called the light-round. Compared to single burner studies [6-10], this last stage has been less well documented. The interest in the need to cope with burner to burner initiation has recently led to a number of studies of ignition on multiple injector systems.

Results of the first large-eddy simulation (LES) of the ignition of a helicopter 
combustion chamber [11] have shown the strong impact of burnt gases volumetric expansion on the flame propagation velocity, but comparisons with experiments were not reported. Flame propagation has been studied experimentally in a linear array of injectors with varying inter-injector spacing with gaseous premixed injection [12] and liquid n-heptane injection [10]. Interinjector distance was found to modify the pattern of flame motion giving rise to two propagation modes. This feature has been retrieved in LES [12] and also observed in an annular combustor $[13,14]$. Nonetheless, such linear configurations do not account for specific phenomena arising in annular geometries. In 2013, two experimental studies have been reported on successful light-round sequences in idealized annular systems, with premixed propane-air injection [15] and methane-air injection [16]. Both studies highlighted the influence of the mixture equivalence ratio and bulk velocity on the light-round duration. Later on, investigations have reported the effects of non-premixed injection [13], inter-injector spacing [13, 14], and liquid fuel injection [17], bringing new insights on the ignition of realistic gas turbines. The first comparisons of light-round simulations with experiments [18, 19] have demonstrated the ability of LES to successfully predict the duration and flame propagation behavior in an annular fully premixed propane-air combustor and for several operating points. A first analysis of the flame propagation pattern has distinguished several stages in the light-round, thus refining the classical three phase decomposition of the process [1]. Accounting for the spray of droplets presents an additional complexity, but is essential when dealing with realistic aeronautical configurations. Prieur et al. [17] carried out the first experimental visualization and characterization of ignition in a 
laboratory scale annular combustor fed with liquid spray. A large-eddy simulation of the corresponding light-round sequence with liquid n-heptane [20] has recently enabled the first comparison of ignition in an annular combustors involving a two-phase flow. Results have shown that the global behavior of the flame and the light-round durations are accurately predicted, validating, for this case, the employed modeling for the dispersed spray with a monodisperse Eulerian approach. Identical phases as those identified in gaseous conditions in [18] have been observed. As noted in previous studies, the effect of burnt gases volumetric expansion yields an enhanced propagating velocity due to an induced flow in the fresh stream.

The nature of the mechanisms controlling the flame propagation velocity during the light-round remains an open question. One possible explanation of the turbulent flame burning velocity might rely on the leading points of the advancing flame fronts [21-24]. Based on observations of particular flow dynamics, a leading point scenario is here considered to identify some of the main mechanisms involved in the flame propagation velocity. Inhibiting or promoting effects linked to the local curvature (and related to the Markstein length) are not considered because their order of magnitude is lower than that pertaining to the flow dynamics.

In the present work, the behavior of these leading points is examined during the ignition of an annular combustor equipped with liquid spray injectors. The experimental and numerical configurations are described in Sec. 2. Numerical results are analyzed for three operating points: the case considered in [20] and two additional operating conditions (Sec. 3). Simulations are first compared with experimental data in terms of light-round duration and 
sector ignition delays. The trajectory and dynamics of the leading point of each flame are then considered. Finally, the observed interactions between the propagating flame front, its leading point and the liquid spray provides new insights on ignition in annular combustors with liquid spray injectors.

\section{Experimental and numerical configurations}

\subsection{Experimental set-up}

The model scale annular combustor MICCA-Spray (Fig. 1) is described in [17]. It comprises sixteen swirl spray injectors equally distributed in a circular pattern. A two-phase mixture of air and liquid n-heptane is injected in the chamber through sixteen swirler units (see the sketch in Fig. 1). The other end of the chamber is open and the exhaust gases are released into the atmosphere.

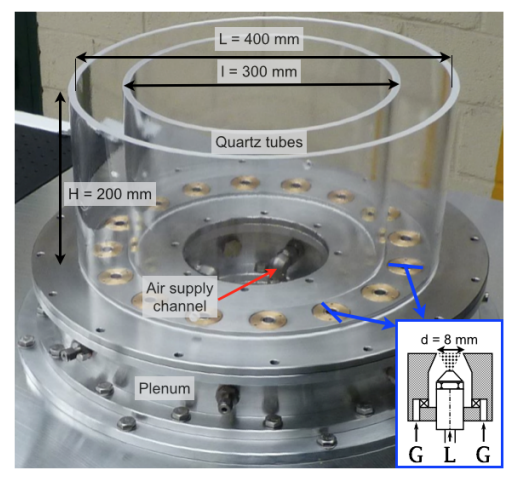

Figure 1: Direct view of the MICCA-Spray combustion chamber [17]. The sketch at the bottom right represents a cut in one swirler unit showing the gaseous ( $\mathrm{G}$ arrows) and liquid (L arrow) injections.

For post-processing purposes, it is convenient to divide MICCA-Spray in two halves, $\mathrm{H}+$ and $\mathrm{H}-$, as shown in Fig. 2, that are symmetrical except for 
the swirl direction, highlighted by the green arrow, oriented in the clockwise direction for all the injectors. Each half of the chamber is decomposed into seven sectors, numbered $S_{1}$ to $S_{7}$ for the $\mathrm{H}+$ side, and $S_{-1}$ to $S_{-7}$ for the $\mathrm{H}$ side. $S_{0}$ and $S_{8}$ respectively correspond to the sector comprising the spark plug and to the opposite one. Each sector is composed of one swirl injector and one sixteenth of the backplane.

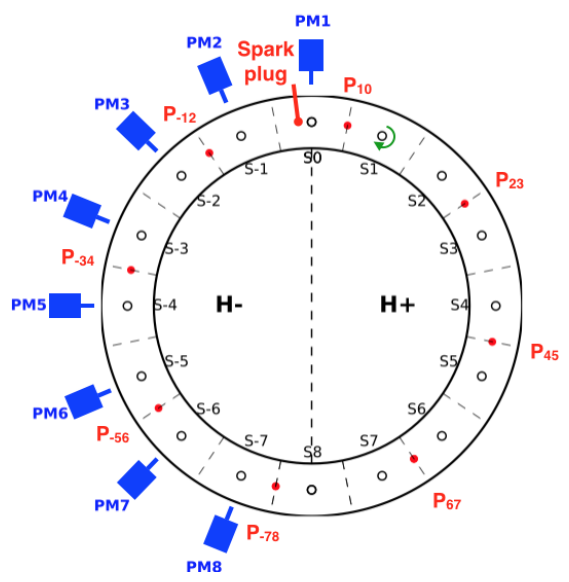

Figure 2: Schematic top view of the MICCA-Spray backplane showing the swirlers positions, photo-multipliers (PM), spark plug and swirl direction.

As indicated in [17] and [20], the evolution of the flame in MICCA-Spray is recorded with a high-speed camera equipped with a $\mathrm{CH}^{*}$ filter featuring a bandwidth of $420-440 \mathrm{~nm}$ and photo-multipliers (PM) that are sensitive to the light emission of the $\mathrm{OH}^{*}$ chemical radical. In the present study, three operating points are considered, for three different global equivalence ratios at the same nominal power $\mathcal{P}=79.3 \mathrm{~kW}: \phi=0.8, \phi=0.89$ and $\phi=1.0$. This is achieved by keeping a constant fuel mass flow rate while varying the air flow rate. 


\subsection{Numerical configuration}

All simulations are carried out with the LES solver AVBP [25], that solves the three dimensional compressible Navier-Stokes equations for reactive flows. A two-step Taylor-Galerkin weighted residual central distribution scheme (TTGC), third order in time and space [26] is used for both gaseous and Eulerian liquid phases. The numerical set-up is identical to that described in [20]. The liquid phase is modeled using an Eulerian mono-disperse approach and the droplets are assumed to have a uniform temperature and their evaporation follows the Abramzon-Sirignano model [27]. The description of the liquid phase was chosen as a compromise between computational cost and accuracy and the parameters of the model, in particular the injected mono-disperse diameter, were carefully evaluated and presented in [20, 28]. In the case described in [20], the calculation of local physical quantities used in the evaporation law, such as viscosity, did not depend on the local gaseous composition. This has been corrected for the three cases, including case $\phi=0.89$, which has been simulated anew, with an improvement of the re-

sults. Combustion of the gaseous n-heptane is represented by a two-step reduced chemical mechanism obtained in $[29,30]$. The unresolved flame structures and the interactions between flame and turbulence are described using TFLES model [31-33] and the efficiency function derived in [34]. The boundary conditions are imposed using characteristic boundary conditions $[35,36]$. In the present study, relight conditions of the combustor are considered: in the experiment, the combustor walls are hot and have reached thermal equilibrium after a period of operation of the system. Under these conditions, one may assume that heat losses from burnt gases are signifi- 
cantly decreased and that adiabatic boundary conditions are applicable at the chamber walls. The parameters for the liquid injection such as droplet diameter and liquid dispersed phase density have been determined through a separate study $[20,28]$. Particular care is taken in obtaining the initial solutions for the three operating points [20]. The computation requires a mesh size of 288 million elements and the simulation of one light-round sequence, including cold flow convergence, takes 3.5 million CPU hours on 6144 processors of the French national cluster CURIE. The ignition is triggered experimentally by a spark plug, located close to the injector in sector $S_{0}$, that generates a propagating kernel. This complex phenomenon is simulated by defining a sphere of hot burnt products that represents the initial hot spot.

\section{Results and discussions}

\subsection{Light-round durations and sector ignition delays}

Calculated light-round durations are compared with those of the experimental sequences. The duration is defined as the delay between the ignition of the $S_{1}$ sector and the merging of the fronts in $S_{8}$. Such a definition allows to focus on the light-round sequence, without taking into account the first instants of the simulation where the physics of the kernel induces some variability in its initial growth. Experimentally, these instants are determined using the recorded images of the flame evolution. Some uncertainty of a few frames arises during the determination of sector $S_{1}$ ignition time which, through the camera frame rate, leads to uncertainties on the light-round duration.

The experimental and numerical values for the light-round durations are shown in Fig. 3. Very good results are achieved for cases $\phi=0.89$, for which 


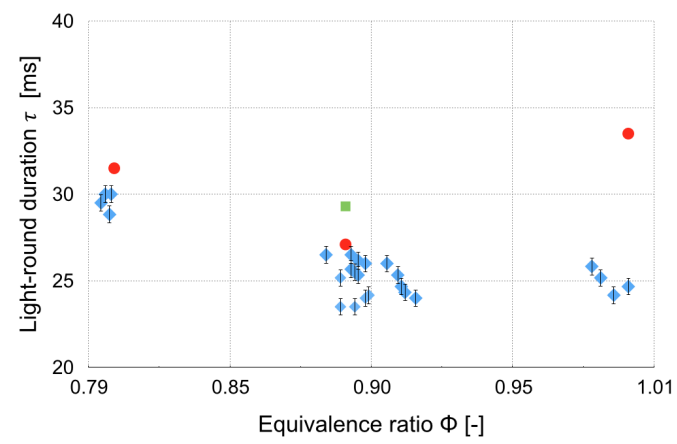

Figure 3: Light-round durations as a function of the global equivalence ratio. Diamond symbols stand for experimental results. The durations predicted by the present simulations are represented by red circles. The green square indicates the light-round from [20] before fixing the evaporation model. Estimated measurement uncertainties are also displayed in this graph.

the predicted duration falls in the experimental scatter of points, and $\phi=$ 0.8 , where the duration is overestimated by $5 \%$, which remains acceptable. However, the relative error of $30 \%$ in the $\phi=1.0$ simulation indicates that this calculation is less adequate, probably due to the locally rich conditions at the leading point which are discussed later.

Another assessment of the simulation consists in comparing durations between the ignition of two consecutive burners. The PM measurements give access to the experimental evolution of the $\mathrm{OH}^{*}$ light emissions in each sector on the $\mathrm{H}$ - side of the chamber. The instant the emission is maximum in one sector is taken as its ignition time, allowing the calculation of the delays between consecutive sectors. For each operating point, two or three measurements are plotted in Fig. 4 as symbols, each symbol standing for one set of measurements, highlighting some variability in the experimental 

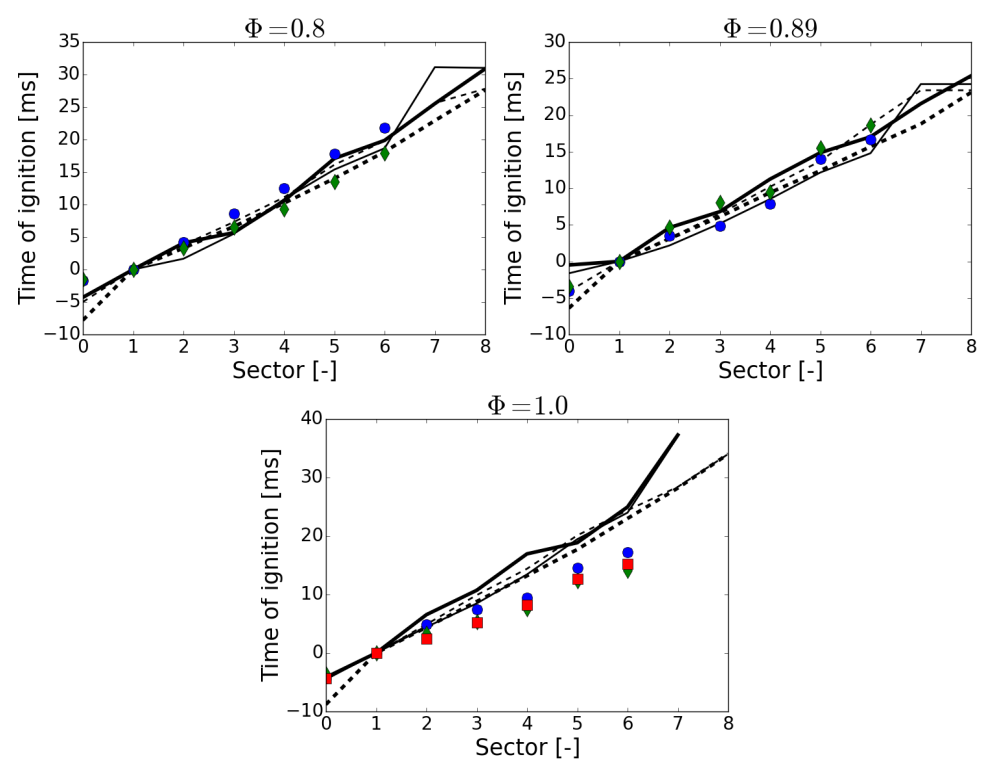

Figure 4: Ignition delay times for each sector in the experiments (in symbols, each set stands for a different experimental sequence) and in the simulations (in the form of lines). Data in the left, middle and right plots respectively correspond to $\phi=0.8$, are $\phi=0.89$ and $\phi=1.0$. Numerical data extracted from the heat release in $\mathrm{H}+$ (thin solid lines) and in $\mathrm{H}$ - (thick solid lines), extracted from the leading point position in $\mathrm{H}+$ : (thin dashed lines) and in $\mathrm{H}$ - (thick dashed lines).

results. In the simulations, the integrated heat release inside each sector is calculated and, similarly to the experiment, the time when a maximum is reached is taken as the sector ignition time. Values are reported in Fig. 4, for both $\mathrm{H}+$ (thin solid lines) and $\mathrm{H}$ - (thick solid lines). As was done for the global light-round duration, the numerical and experimental results are synchronized with respect to the ignition of the first sector $\left(S_{1}\right.$ or $\left.S_{-1}\right)$, that sets the origin of times. Cases $\phi=0.8$ (Fig. 4 left) and $\phi=0.89$ (Fig. 4 center) show an excellent agreement between experiment and simulation. Both $\mathrm{H}+$ 
and $\mathrm{H}-$ evolutions are close to that of the experimental sequence, indicating that the accuracy observed in the global light-round duration is linked to the ability of the simulation to capture the flame propagation velocity. On the $\mathrm{H}+$ side of case $\phi=0.8$, the plot shows that the flame front slows down between sectors $S_{6}$ and $S_{7}$, indicating that the $5 \%$ difference observed in the light-round duration is due to a deceleration of one of the flame fronts towards the end of the sequence, when the two fronts collide head on and the flow is notably modified by the flame. Finally, the plot on the right in Fig. 4 allows to identify the source of error for the case $\phi=1.0$ for both sides of the chamber. The simulation systematically overestimates the ignition delay between sectors, leading to a gradually increasing error in ignition time, which explains the larger error in the light-round duration. Contrarily to the previous case, the error does not arise towards the end of the sequence, but is formed by an accumulation throughout the simulation, indicating that the propagation mechanisms are less well captured under these conditions.

\subsection{Leading points dynamics}

Similarly to the observations detailed in [20], the phases identified in $[18,19]$ can be retrieved in the three cases simulated in this study (not shown). Once the kernel has propagated to the vicinity of the injector (phase I) in $S_{0}$, an arch-like flame is formed that propagated towards sectors $S_{1}$ and $S_{-1}$ and the chamber exit, corresponding to phase II. Upon reaching the exit, the flame separates into two fronts, thus going into phase III, where the propagation is driven from the bottom of the chamber, until the fronts merge in the other side of the annulus (phase IV). These phases are observed in both experiment and simulation, for all three cases, showing that the numerical set-up is able 


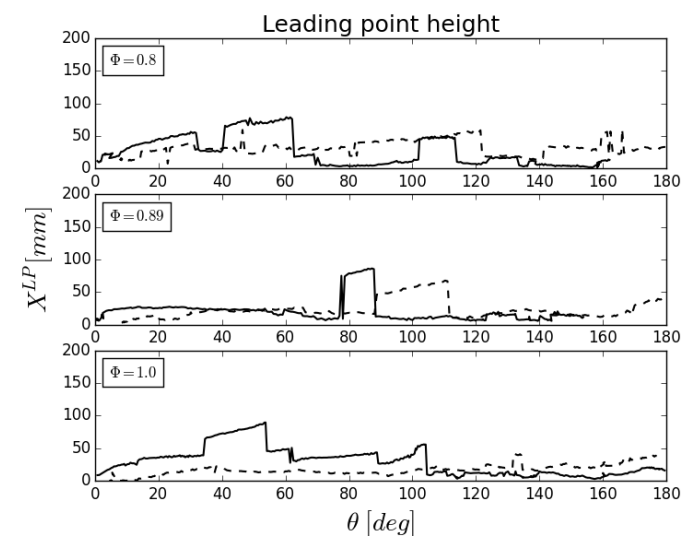

Figure 5: Leading points height against their azimuthal position for $\mathrm{H}+$ (solid lines) and H- (dashed lines) and all three cases: $\phi=0.8$ at the top, $\phi=0.89$ in the middle and $\phi=1.0$ at the bottom.

to retrieve the behavior of the flame, even without the correct propagation speed in case $\phi=1.0$.

For a closer study of the flame and an understanding of its propagation mechanisms, it is interesting to track its leading point (LP). For each half chamber, the leading point is defined as the most forward point in the azimuthal direction on the $c=0.9$ iso-surface, $c$ being the progress variable defined as $c=\left(Y_{\mathrm{CO}_{2}}+Y_{\mathrm{CO}}\right) /\left(Y_{\mathrm{CO}_{2}}^{e q}+Y_{\mathrm{CO}}^{e q}\right)$, which ensures its monotony through the flame front. The value of $c=0.9$ was chosen because it is close to the peak of heat release in the flame in the Arrhenius law, but the same post-processing has been performed for the leading point defined by tracking $c=0.1$ and $c=0.5$ iso-surfaces. This yields qualitatively similar results leading to the same conclusions. For example, the effect of the progress variable threshold on the leading point trajectory is given in supplemental material.

The shape of the flame fronts is strongly influenced by the local flow field, 
so there can be a competition between several flame elements. Due to its definition, the LP's trajectory features some discontinuities in its evolution and characteristics. Instants where the LP crosses each injector azimuthal position are plotted in Fig. 4 as dashed lines (thin dashed lines for $\mathrm{H}+$ and thick dashed lines for $\mathrm{H}-$ ), synchronized at sector $S_{1}$ or $S_{-1}$ as with the other data sets. The consistency between the data extracted from the LP and from the sector-integrated heat release, which is a more global measure, confirms that one possible scenario for the flame propagation involves the leading-point entraining the turbulent flame brush.

Some insight can be gained by observing the trajectory of the LP and examining the interaction of the flame tip with the aerodynamic flow. Figure S2 shows the axial position of the LP for both halves of the chamber and for all three cases. For each case and during the whole propagation, the LP is located below $50 \mathrm{~mm}$, which corresponds to the bottom $25 \%$ of the chamber. The LP in H- (dashed lines) exhibits a relatively smoother behavior, with fewer discontinuities. On the $\mathrm{H}+$ side however, some common features can be identified (less pronounced for $\phi=0.89$ ). During the first third of the angular propagation, which corresponds to phase II, discontinuities indicate that the LP is lifted up due to the arch-like flame. The distance of the LP with respect to the chamber backplane gradually increases until it is suddenly brought back. This trend is repeated several times, until some point after the half of the trajectory, which varies depending on the case, where the LP definitely drops down near the backplane. This behavior suggests that favorable conditions exist near the chamber inlet, probably due to the presence of the swirling flow generated by the injectors in combination with 
richer pockets where droplets are trapped by the outer recirculation zones. This can be evidenced by looking at the value of the local gaseous equivalence ratio at the leading point, plotted in Fig. 6, for the three cases. The equivalence ratio is computed based on the gaseous species atoms balance. A horizontal black dashed line highlights the injected global equivalence ratio $\phi$. In all cases and during the whole propagation, the LP is systematically in a mixture that is richer than $\phi$. Fewer discontinuities are observed here than in the LP position, indicating that the equivalence ratio does not vary much in the LP propagation region and therefore that the competing flame tips burn at similar $\phi$. When the flame fronts are located in the last third of the chamber, some large swings occur in the local equivalence ratio evolution that can be surprising. The tangential positions where these events take place correspond to the positions of the injectors, suggesting that in the presence of the highly turbulent sprays, the flame fronts encounter large $\phi$ variations, due in particular to the presence of pockets of liquid fuel. The presence of the series of swirling jets can also be an explanation for this concentration of fuel vapor at the bottom of the chamber. This is further discussed in the next section.

\subsection{Flame-spray interactions}

As noted in other similar studies $([11,15,18,19])$, the volumetric expansion of the burnt gases in the semi-confined chamber has a notable impact on the fresh stream before the flame. It is therefore interesting to analyze its interaction with the liquid spray. This can be observed by considering a cylindrical cut inside the chamber and unfolding this surface. In this rep-

resentation the spark plug corresponds to the left and right boundaries of 


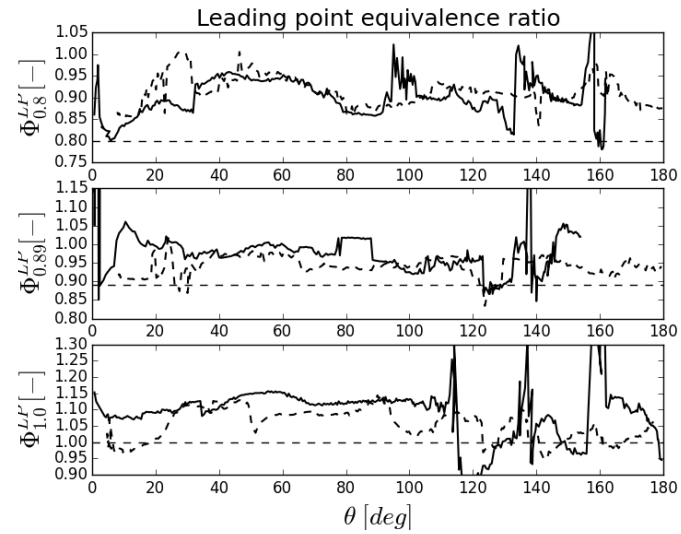

Figure 6: Time evolution of the equivalence ratio at the leading point in $\mathrm{H}+$ (solid lines) and $\mathrm{H}$ - (dashed lines) and for $\phi=0.8$ (top), $\phi=0.89$ (middle) and $\phi=1.0$ (bottom). The horizontal black dashed lines mark the global equivalence ratio for each case.

the unfolded cylindrical surface and the flames propagate towards the center of the image. Figure 7 shows the gaseous tangential velocity $u_{\theta}$ field (top image) and the liquid mass density $\alpha_{l} \rho_{l}$ (bottom image), for the case $\phi=0.8$ at an instant chosen to observe phase III, where two propagating fronts are present. Similar behaviors are observed in the other operating cases. It appears clearly that the propagation of the flames generates an azimuthal flow that pushes the fresh gases several sectors ahead of the flame. During the light-round, the leading point evolves in this region of large azimuthal velocity which dominates the LP velocity (see Fig. 8). The bottom image in Fig. 7 indicates that the flow induced ahead of the flame perturbs the liquid phase distribution, evidenced by the sprays injected by the un-ignited injectors, which are inclined away from the flame, a feature that is observed experimentally. Some pockets of droplets are also created and pushed away from the flame fronts, forming patterns similar to those found with jets in 


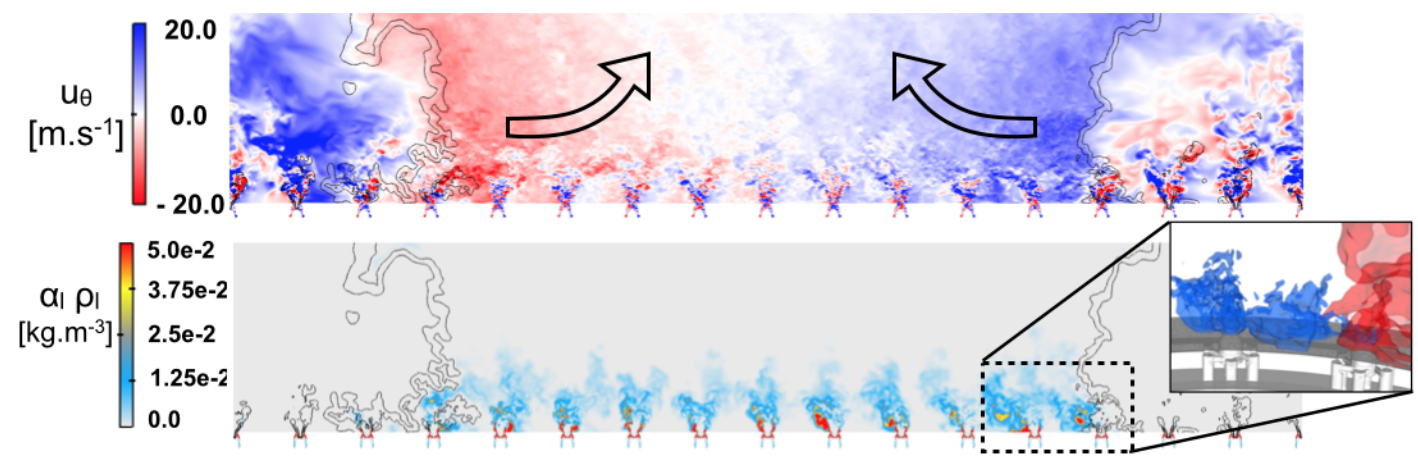

Figure 7: Top: visualization of the tangential gaseous velocity on a cylinder of radius $r=0.175 \mathrm{~m}$ unfolded on a plane surface for the case $\phi=0.80$ at instant $t=17 \mathrm{~ms}$. Bottom: visualization of the liquid mas density $\alpha_{l} \rho_{l}$ on the same unfolded plane. The radius was chosen so that the cut would cross the center of each injector. The lateral sides of the unfolded cylinder correspond to the location of the first ignited injector. Tangential velocities are counted positive from left to right. Two iso-lines of the progress variable $c=0.1$ and $c=0.9$ (in black) highlight the position of the flame fronts. The insert on the right represents the impact of the flame progress (red iso-surface) on the liquid spray, evidenced by a blue iso-surface at $\alpha_{l} \rho_{l}=0.01 \mathrm{~kg} \cdot \mathrm{m}^{-3}$.

cross-flows (see insert on the right in Fig. 7). This phenomenon is due to the strong azimuthal velocity which forms wakes on the downstream side of the swirling streams established by the different injectors.

The induced flow impact on the liquid phase can be further evidenced by observing the temporal evolution of some quantities at selected points in the chamber. Figure 9 displays the evolution of $\alpha_{l} \rho_{l}$ and the local gaseous equivalence ratio $\phi_{g}$, for the three cases, at the point $[x=2.5 \mathrm{~mm}, r=0.175 \mathrm{~m}$, $\theta=9 \pi / 8]$, which corresponds to a point located near the chamber back-plane at the frontier between $S_{4}$ and $S_{5}$, on the $\mathrm{H}+$ side. This point is chosen to be near the leading point trajectory. To highlight the crossing of the flame, 


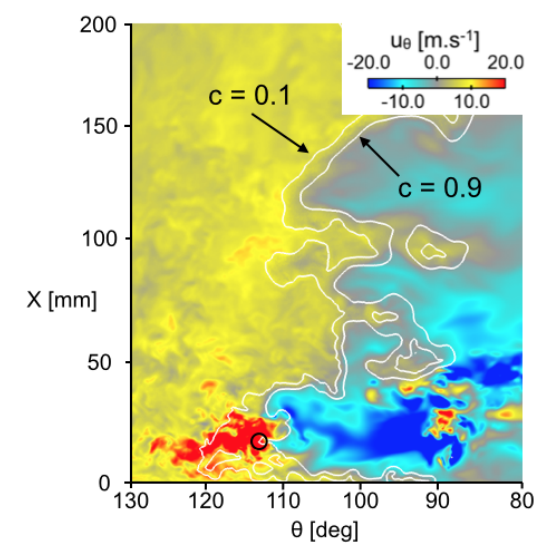

Figure 8: Zoom on the flame front leading point (LP) area on an unfolded cylindrical cut at $r=r_{L P}$, colored by the tangential velocity. The flame is evidenced by white iso-lines of the progress variable $c=0.1$ and $c=0.9$. The LP is highlighted by the black circle.

the progress variable $c$ is also plotted (dotted line). In all cases, the same trend is observed; although a steady state regime had been reached before the ignition, the local liquid mass density begins to increase approximately $10 \mathrm{~ms}$ before the crossing of the flame (evidenced by the increase in the progress variable). This shows that an accumulation of liquid is created by the flow generated ahead of the flame fronts, so that the local conditions seen by the flame differ from those corresponding to the steady-state cold two-phase flow field. As a consequence, the local gaseous equivalence ratio is increased close to the flame front, when this accumulation of droplets evaporates in the vicinity of the flame. This increase is expected to be even larger for fuels that are less volatile than n-heptane. It appears that in the three cases under consideration, the modification of the initial heterogeneous field of equivalence ratio by the flame propagation is not negligible and systematically yields an equivalence ratio at the LP that is larger than the global value. 
The larger error of the simulated case $\phi=1.0$ shown in Fig. 4 could be due to a more pronounced heterogeneity with rich conditions prevailing in the leading point region, a situation that is less well tackled by the combustion model (see Fig. 6).

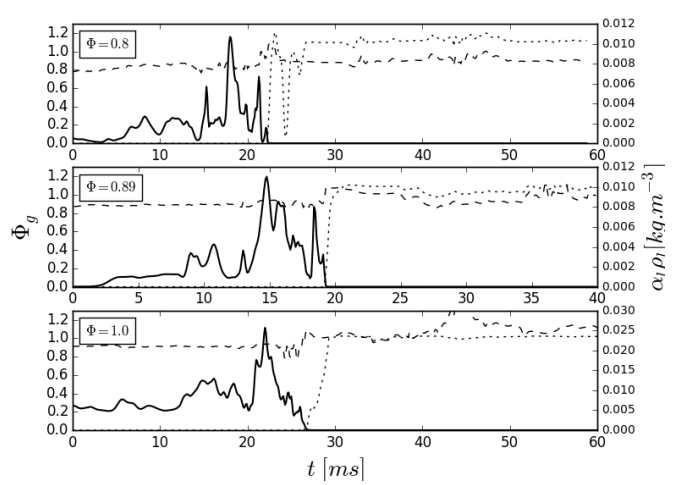

Figure 9: Temporal evolution of the liquid mass density (solid lines, right axis) and the gaseous equivalence ratio (dashed lines, left axis) for the three cases $\phi=0.8$ (top), $\phi=0.89$ (middle) and $\phi=1.0$ (bottom) at point $[x=2.5 \mathrm{~mm}, r=0.175 \mathrm{~m}, \theta=9 \pi / 16]$. The evolution of the progress variable $c$ is added (dotted lines, left axis) to highlight the crossing of the flame.

\section{Conclusion}

Large eddy simulations of the light-round sequence in a laboratory scale annular combustor have been carried out with liquid spray injection using an Eulerian framework and a mono-disperse representation of the spray. Three different cases with varying global equivalence ratios are compared to experimental data. Cases $\phi=0.8$ and $\phi=0.89$ indicate that the simulation is able to accurately predict the light-round duration as well as the ignition delay between the injectors, while the case $\phi=1.0$ is less accurately described with 
an underestimation of the absolute flame velocity. It is found that the volumetric expansion resulting from chemical conversion in the flame induces an azimuthal velocity in the fresh stream at a distance of several sectors ahead of the flame. This induced flow modifies conditions in the fresh stream. A detailed analysis of local dynamics is carried out through the definition of a leading point for each flame front. The three cases investigated present similar preferential leading point trajectories in the combustor. Analysis of local values at the leading point indicates that the flow induced by the flame interacts with the liquid phase, modifying the liquid volume fraction in the wakes of the swirling jets established by the various injectors. This gives rise to a heterogeneity in composition and higher equivalence ratios in the fresh stream in front of the flames. These two features influence the leading point motion and trajectory in the chamber and affect the absolute flame velocity. Future investigations will consider the impact of more accurate spray modeling taking into account the polydispersity of the liquid phase. It is also intended to change the turbulent combustion model to improve predictions under heterogeneous conditions and high equivalence ratio values. Further analysis will be necessary to assess the leading-point and mean flame brush scenarios and their probable interplay in the flame propagation process.

\section{Acknowledgments}

This work was granted access to the HPC resources of TGCC and IDRIS under allocations GENCI 2017-A0022B10118 and PRACE n14-2016153551. This work was supported by grant ANR14-CE23-0009-01 of the French Agence Nationale de la Recherche in the TIMBER project. 


\section{References}

[1] A. Lefebvre, D. R. Ballal, Gas Turbine Combustion, Taylor \& Francis, London, 2010.

[2] D. R. Ballal, A. H. Lefebvre, , Symp. (Int.) Combust. 15 (1) (1975) 1473 $-1481$

[3] V. Kurdyumov, J. Blasco, A. Sánchez, A. Liñán, , Combust. Flame 136 (3) (2004) $394-397$.

[4] S. Shy, C. Liu, W. Shih, , Combust. Flame 157 (2) (2010) 341 - 350.

[5] C. Cardin, B. Renou, G. Cabot, A. M. Boukhalfa, Combust. Flame 160 (8) (2013) $1414-1427$.

[6] T. Marchione, S. Ahmed, E. Mastorakos, Combust. Flame 156 (1) (2009) $166-180$.

[7] W. P. Jones, A. Tyliszczak, Flow Turb. Combust. 85 (3-4, SI) (2010) 711-734.

[8] V. Subramanian, P. Domingo, L. Vervisch, Combust. Flame 157 (3) (2010) 579-601.

[9] L. Esclapez, E. Riber, B. Cuenot, Proc. Combust. Inst. 35 (3) (2015) $3133-3141$.

[10] J. Marrero Santiago, A. Verdier, C. Brunet, A. Vandel, G. Godard, G. Cabot, A. Boukhalfa, B. Renou, J. Eng. Gas Turbines Power 140 (2). 
[11] M. Boileau, G. Staffelbach, B. Cuenot, T. Poinsot, C. Bérat, Combust. Flame $154(1-2)(2008) 2-22$.

[12] D. Barré, L. Esclapez, M. Cordier, E. Riber, B. Cuenot, G. Staffelbach, B. Renou, A. Vandel, L. Y. Gicquel, G. Cabot, Combust. Flame 161 (9) (2014) $2387-2405$.

[13] E. Machover, E. Mastorakos, Exp. Therm. Fluid Sci. 73 (2016) 64-70.

[14] E. Machover, E. Mastorakos, Combustion. Flame 178 (Supp. C) (2017) $148-157$.

[15] J.-F. Bourgouin, D. Durox, T. Schuller, J. Beaunier, S. Candel, Combust. Flame 160 (8) (2013) $1398-1413$.

[16] E. Bach, J. Kariuki, J. R. Dawson, E. Mastorakos, H. joerg Bauer, AIAA, 2013-1182

[17] K. Prieur, D. Durox, J. Beaunier, T. Schuller, S. Candel, Proc. Combust. Inst. 36 (3) (2017) 3717-3724.

[18] M. Philip, M. Boileau, R. Vicquelin, T. Schmitt, D. Durox, J.-F. Bourgouin, S. Candel, J. Eng. Gas Turbines Power 137 (3).

[19] M. Philip, M. Boileau, R. Vicquelin, E. Riber, T. Schmitt, B. Cuenot, D. Durox, S. Candel, Proc. Combust. Inst. 35 (3) (2015) 3159 - 3166.

[20] T. Lancien, K. Prieur, D. Durox, S. Candel, R. Vicquelin J. Eng. Gas Turbines Power 140 (2).

[21] J. F. Driscoll, Prog. Energy Combust. Sci. 34 (2008) 91-134. 
[22] A. N. Lipatnikov, J. Chomiak, Prog. Energy Combust. Sci. 31 (1) (2005) $1-73$.

[23] A. Amato, T. C. Lieuwen, Combust. Flame 161 (5) (2014) 1337-1347.

[24] A. Amato, M. Day, R. K. Cheng, J. Bell, T. Lieuwen, Proc. Combust. Inst. 35 (2) (2015) 1313-1320.

[25] T. Schönfeld, M. Rudgyard, AIAA Journal 37 (11) (1999) 1378-1385.

[26] O. Colin, M. Rudgyard, J. Comput. Phys. 162 (2) (2000) 338 - 371.

[27] B. Abramzon, W. Sirignano, Int. J. Heat Mass Transfer 32 (9) (1989) $1605-1618$.

[28] T. Lancien, N. Dumont, K. Prieur, D. Durox, S. Candel, O. Gicquel, R. Vicquelin, in: Int. Conf. on Multiphase Flow, Florence, May 2016.

[29] D. Paulhiac, Modélisation de la combustion d'un spray dans un bruleur aéronautique, Ph.D. thesis, INP Toulouse (2015).

[30] F. Shum-Kivan, J. M. Santiago, A. Verdier, E. Riber, B. Renou, G. Cabot, B. Cuenot, Proc. Combust. Inst. 36 (2) (2016) 2567-2575.

[31] T. Butler, P. O'Rourke, Symp. (Int.) Combust., 16 (1) (1977) 1503 1515.

[32] O. Colin, F. Ducros, D. Veynante, T. Poinsot, Phys. Fluids 12 (7) (2000) 1843-1863.

[33] J. P. Legier, T. Poinsot, D. Veynante, in: Proc. Sum. Prog., CTR, NASA Ames/Stanford Univ., 2000157168 
[34] F. Charlette, C. Meneveau, D. Veynante, Combust. Flame 131 (1-2) (2002) $159-180$.

[35] V. Moureau, G. Lartigue, Y. Sommerer, C. Angelberger, O. Colin, T. Poinsot, J. Comput. Phys. 202 (2) (2005) $710-736$.

[36] T. Poinsot, S. Lele, J. Comput. Phys. 101 (1) (1992) $104-129$. 


\section{List of supplemental material}

Figure S1: Comparison of the azimuthal speed $V_{L P}=r_{L P} \frac{d \theta_{L P}}{d t}$ of the leading point (in red) and the flow azimuthal velocity at the same point (in black) plotted with respect to the leading point angular position for $\mathrm{H}+$ (right) and $\mathrm{H}-$ (left). Results are given for the three cases $\phi=0.8$ (top), $\phi=0.89$ (middle) and $\phi=1.0$ (bottom).

Figure S2: Leading points trajectories projected on the chamber backplane. Top: the blue, red and green lines respectively stand for $\phi=0.8, \phi=0.89$ and $\phi=1.0$. The LP is defined on the $c=0.9$ iso-surfaces. Bottom: Trajectories for case $\Phi=0.8$ for the LP defined on three different iso-surfaces, $c=0.1$ (blue), $c=0.5$ (red) and $c=0.9$ (green). 